\title{
SCENARIO-BASED SIMULATION OF CRITICALITY CONCERNING THE TRANSPORTATION OF DANGEROUS GOODS
}

\author{
Dorel BADEA* \\ dorel.badea@yahoo.com \\ Ghiță ARAMĂ* \\ micuarama@yahoo.com \\ Marian COMAN* \\ coman.marian@gmail.com \\ Olga Maria Cristina BUCOVET,CHI** \\ olgabucovetchi@yahoo.com \\ Gabriel MĂNESCU* \\ manescug@yahoo.com \\ * "NICOLAE BÄLCESCU" LAND FORCES ACADEMY, SIBIU, ROMANIA \\ ** POLITEHNICA UNIVERSITY OF BUCHAREST, ROMANIA
}

\begin{abstract}
:
The critical infrastructure protection domain, through its social implications, is a relatively new research topic, and a science in this regard is not setup yet. Its complexity, through the operational subsumed areas, through the interdependencies and cascading possible effects, through the many facets for investigation, is a special one which imposes specific approaches. This paper intends to continue the investigations in this field, which are conducted in an individual manner or by research teams, by authors with concerns in this regard who agreed to allocate to the topical subject a special attention based on its importance, beyond an exclusive approach - as a special topic. This time, there are brought into attention the issues related to chemical industry sector correlated with actual associated implications of necessary transportation activities in this field. Simulation-based scenario is the main technique employed as a research methodology by using dedicated software.
\end{abstract}

\section{KEYWORDS:}

Chemicals, transportation, criticality, urban security, scenario 
1. Particularities of Analysis Related to Chemical Industry and Transportation of Dangerous Goods as the Subject of Critical Infrastructure

Among the infrastructure sectors regulated at national or international level, in a stand-alone manner or in a combination with other sectors, we can identify the chemical industry. Its main elements of criticality are referring to storage tanks/ warehouses of chemical reagents and dangerous substances (hydrochloric acid, sodium hydroxide, hydrate hydrazine, cyanides etc.) and also to processing capacity, usage, transportation and supply of related chemicals. At the same time, based on the variety of raw materials and finished products routinely made, the chemical industry is among the industrial branches that quickly evolved, in a spurred development way, and is linked to other sectors which are supported by it or are in a cooperative relations across a national or regional economy. Corroborating the two issues presented so far, and in accordance with the proposed title for development during this scientific approach, it is evident that we are talking about a system of systems with multiple dependencies and interdependencies (Figure no. 1).

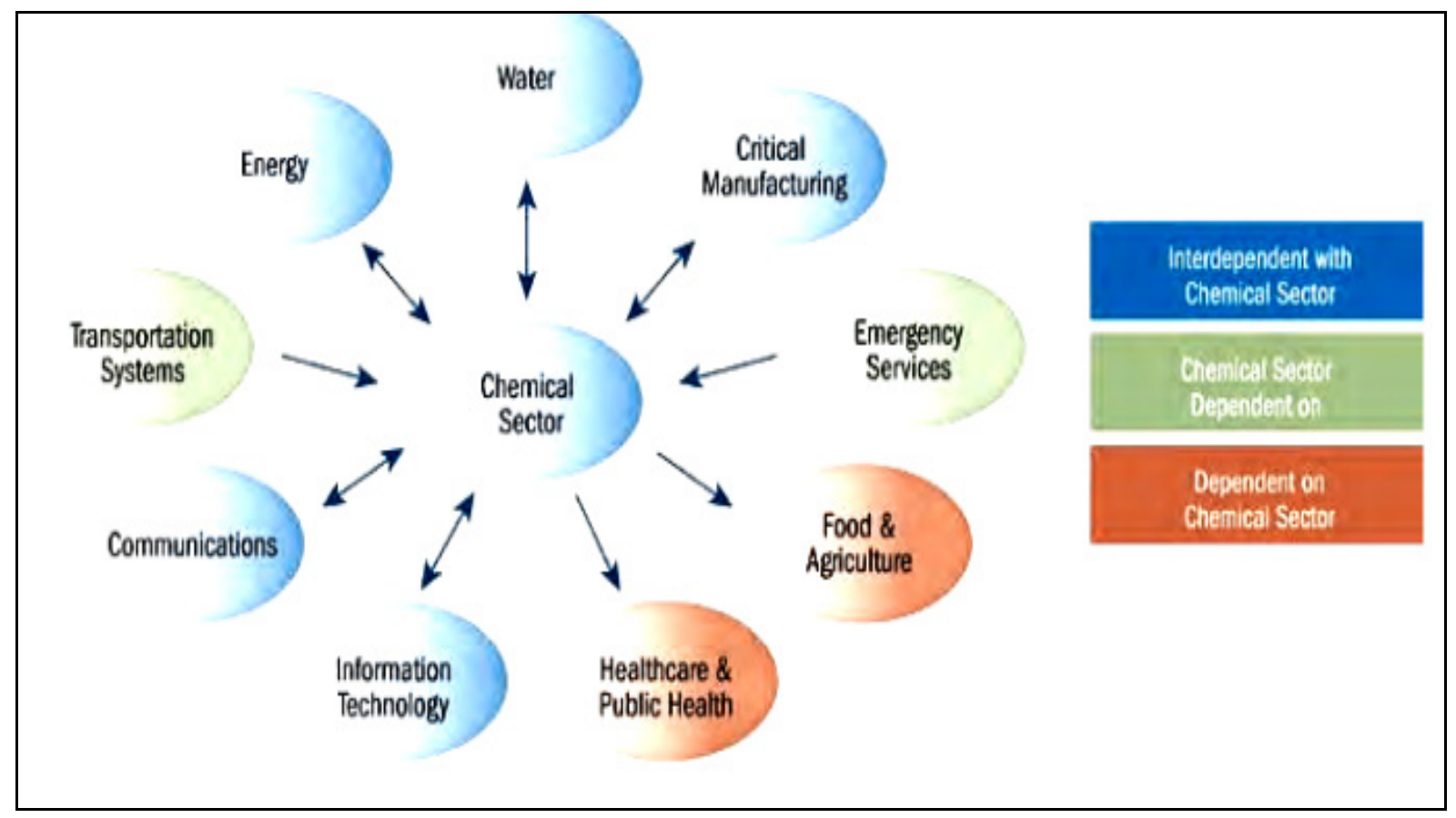

Figure no. 1. The highlighting of dependencies and interdependencies related to chemical sector (source: Homeland Security, 2010)

From a legal point of view related to the regime of chemicals handling and specific required conditions to be met by transportation operators, we are limited by a heavily regulated register at the national and European level. Several landmarks in this domain are following: Decision no. 1408, $4^{\text {th }}$ of November 2008, linked to classification, packaging and labeling of dangerous substances; Decision no. 804, adopted on $25^{\text {th }}$ of July 2007 , linked to controlling of major accident hazards involving dangerous substances; Government Decision of Romania no. 642 , adopted on $29^{\text {th }}$ of June 2005 , linked to approval of the criteria for the classification of administrative-territorial units, public institutions and economic operators in terms of civil protection, based on specific types of risks; Law no. $92,18^{\text {th }}$ of March 2003, linked to Romania's accession to the Convention on the Transboundary Effects of Industrial Accidents, 
adopted at Helsinki on $17^{\text {th }}$ of March 1992, etc.

"National Strategy Guide for country defense related to period of time 2015-2019" presents an interesting approach by placing the chemicals in this way: "dual-use items: products and goods, software and technology normally used for civilian purposes but which, because of their nature, may have military applications or contribute directly or indirectly to the development and production of weapons of mass destruction (nuclear, biological, chemical and radiological)". (Presidencial Administration, 2015, p. 9)

\section{Simulation of a Scenario in the Field - Fundamentals}

If we look to the importance of using scenarios and simulations for complex domains linked to security, as expressed in the previous paragraphs, the criticality of activity taken into consideration for this article is based on robust factitive technical foundations. Notwithstanding, a contemporary common frame of research stands out as a result of both civilian and military valences - is the research framework of urban security.

The hindermost concept is defined by Gurza Vlad Gabriel (2015) as being "a discipline which interdisciplinary refers to the elaboration of policies, methods and standards that lead to enhanced level of security into social environment, an increase of the individual safety feeling in a certain field or a region and also refers to the study of the asymmetric attacks' risks, conditions which are favorable for the attack, to the solutions in order to prevent the attacks and eventually, refers to the solutions for the management of the postdisaster situations". The subject is new brought in topicality, regarding the political, economic, social and technological context, in which, the limit between determinist and probabilistic is getting more and more fragile. Although the concerns with this have roots in the past, nationally speaking there is the name of Cincinat Sfinţescu who in 1939 was writing the piece of work "The urban defense", of which the main purpose is the effects' analysis of the airline attacks with fire-bombs, explosive-bombs and gasbombs, suggesting as well some urban defense measures against this kind of threats.

In this register of analysis, the importance of some approaches of these phenomena is also emphasized in the field of the research program's architecture, Horizon 2020 (EC, 2013), in which not only is admitted that "the citizens of Europe are more and more affected by different forms of insecurity starting with murder, violence, terrorism, natural disasters or manmade disasters, cyber-attacks, confidentiality abuses and ending with other forms of social and economic disturbances" but is also stated that is necessary research activities to raise in an ambitious and bold way the understanding, prevention, preparation and protection against security threats.

At the same time, regarding the possibility, the advantages and the theoretical and practical limits of achieving simulation scenario for this kind of complex situations, we have to emphasize that we do not have to deal with a panacea for solving problems, but we have to deal with a tool in a field of a methodology. In order to do this, besides the classic and conventional addresses from the published literature of modeling, simulation and scenarios' development, another interesting point of view is endorsed by Erdal Cayirci and Dusan Marincic (2009, p. 177) who consider that theoretical development of a scenario does not have to focus on what will happen, but more likely on the necessary and adequate conditions for a given result to be obtained. We do believe, thus, that the more conventional address under which the scenario of a simulation represents a description of a situation or of a component part, focusing on the interactions of some tasks, must be taken into consideration, at least for the case speaking of, in a more flexible manner, taking account of the context particularities (emergency situations generated by 
industrial risks, civil protection, etc).

Starting with the binomial proximal gender-specific differences, before the exemplification of a scenario type for the situation cropped from reality, with its basic design founded on the triad rules, actors and resources, some possible situations specific for the chosen field can be:

- the transport of a kind of chemical substance from a provider or a holder of a processing facility using one way of transport or more (convoy);

- terrorist attack against the transportation capabilities near to the production plant or next to an urban concourse like a city with a local or a regional administrative office (Virca \& Mihăilă, 2013, p. 218);

- technical error (accident) during transportation activity to a transporting vehicle with implications over the security of the transported substance (Virca, 2014);

- unexpected damage to one means of transportation as a result of local unsuitable conditions related to highway.

From all the attributes of such a situation, there were taken into account especially the technical physically-chemical parameters regarding the transported substance, the transport capacity, local weather conditions in the moment of the incident. Features considered aims to identify and analyze the subsystems' elements with significant impact on the operation and the accomplishment of the tasks within the system, and on the replicated complex event in the field.

It is remarkable the preparation and running of a simulation exercise in the field, organized at the national level on $11 / 10 / 2016$, under coordination of the Inspectorate for Emergency Situations "General Magheru" - Vâlcea County. The central theme of simulation exercise was the limitation and removal of the major technologic accident's consequences involving dangerous substances. The exercise scenario took into account the following elements (http://jurnalvalcean.ro): “At 12.00, in the liquefied gas storage park, the rehabilitation activities were executed on the access stairs of sphere-tank designated for propylene storage. During unloading of a tanker truck which was transporting the propylene, due to the leaks in one of the flange connection located under the propylene sphere-tank, significant amounts of propylene has been lost. An explosion took place and a strong fire followed the blast occurred due to both accumulated vapors and open source of fire coming from repairing activities executed in the nearby area. As a result of the release into atmosphere about 400 tons of propylene and exceeding the economic operator response capacity, the operator dispatcher acted centralized alarm by signaling 'EMERGENCY DISASTER' on the entire industrial platform for providing notification to all economic operators from industrial platform, to the local committee of Râmnicu Vâlcea municipality, and to the Operational Centre of the Inspectorate for Emergency Situations".

Analyzing the relevant casuistry in this area, two eloquent situations are given below.

In 2013, in Baltimore, on the east coast of the US, a freight train carrying chemicals (one of the included products for transportation was classified by the Department of Transport as dangerous substance) exploded after colliding with a truck and derailed (in total being 15 of the train cars). As a result, although the column of smoke was going up, for several hours, over the place of the accident, the local residents were not evacuated.

In Romania, on 05/24/2004 in the town Mihăileşti (Buzău) on European road E85 (32 km south of Buzău), there was an explosion due to the crash of a truck carrying 20 tons of ammonium nitrate. The blast's result was a real disaster, 18 people losing their lives, and another 13 were seriously injured. It was also noted that a crater with a deep of 6.5 meters and a diameter of 21 meters was formed around the site of the explosion and pieces of metal were disposed of within 200 meters affecting the roofs of several houses in the 
area (Bunilă, 2013).

Following the occurrence of such accidents, as identified and need to be learned lessons the paramount ways are: the testing of emergency plans and procedures viability, with particular focus on actual knowledge and level of training for all personnel involved in intervention; rising of awareness level related to security compliance of the working arrangements of plants or transportation capacity linked to hazardous substances; the removal of any overlapping situations linked to institutions' involvement which provide specific functions' support in case of a major industrial accident.

\section{Using ALOHA Software for a Chemical Risk Event Simulation}

Based on previous experiences, specialized organizations, with extensive concerns regarding population's safety in cases of chemical accidents, developed detailed action procedures which represent the foundation of personnel training, authorized to step in for reducing the effects and eliminating the consequences of this kind of incident. An example is provided by the U.S. Department of Transportation through Administration Safety Pipeline and Hazardous Materials which, in 2016, edited a response guide for dangerous situations "2016 Emergency Response Guidebook" an action guide for the first people arrived during the initial phase of a transportation incident, where hazardous materials are involved.

In the authors' opinion, this paper aims and succeeds to provide a real support for the specialists who are firstly involved right in the moment when the incidents of such amplitude take place and by whose good management of the event depending numerous people's lives. It is also succeeded putting down the right information into the paper, from the algorithm which has to be applied by personnel involved in the intervention, to the technical information regarding the identification of the risk (nameplates, transport containers, knowledge sheets linked to hazardous materials) forming an action algorithm for emergency situations in a fluent and logical organization.

The situation emphasized in this event simulation is based on a scenario where tanker truck transporting chlorine (liquefied gas) is involved in an accident, and the release into the environment of the tank content is putting in danger the local population, as well as the traffic participants. Equally, the impact upon the environment could be devastating, with major consequences on the ecosystem's diversity.

The application software through which the event simulation was done is called Aloha Software, (EPA, 2016) was tailored by the US Environmental Protection Agency, and it can be downloaded by any user from their official website. The application represents a computer program capable to model hazardous areas in order to plan coherent and fast chemical urgencies. For a better visualization of potential contaminated areas with hazardous chemicals, as well as for achieving a realistic and detailed action plan, besides Aloha software the user may also take into consideration the Marplot software, which is used for mapping and is capable of exporting risk zones resulted after data analyzing provided by Aloha software. Both Aloha and Marplot are included in the system of software applications named CAMEO (ComputerAided Management of Emergency Operations), a system designed for planning and answering to the emergency situations.

Running this type of software is relatively easy and based on a detailed algorithm of data gathering required in the achievement of chemical risk zones' simulation. Initially, there is a need by any data gathering concerning the location where the event is taking place: area, coordinates, type of terrain, building types, date and hour of the event simulation. Being settled in a very clear manner the location of the event occurrence, next activity is to insert the name of the chemical 
agent released in the atmosphere, and then the application software will submit a technical data specific to it. Next step is represented by the establishment of the atmospheric conditions (the speed and the direction of wind, the type of terrain, coverage of the sky, temperature and humidity) data which can be introduced manually or can be gathered from the specialized software systems (Figure no 2).

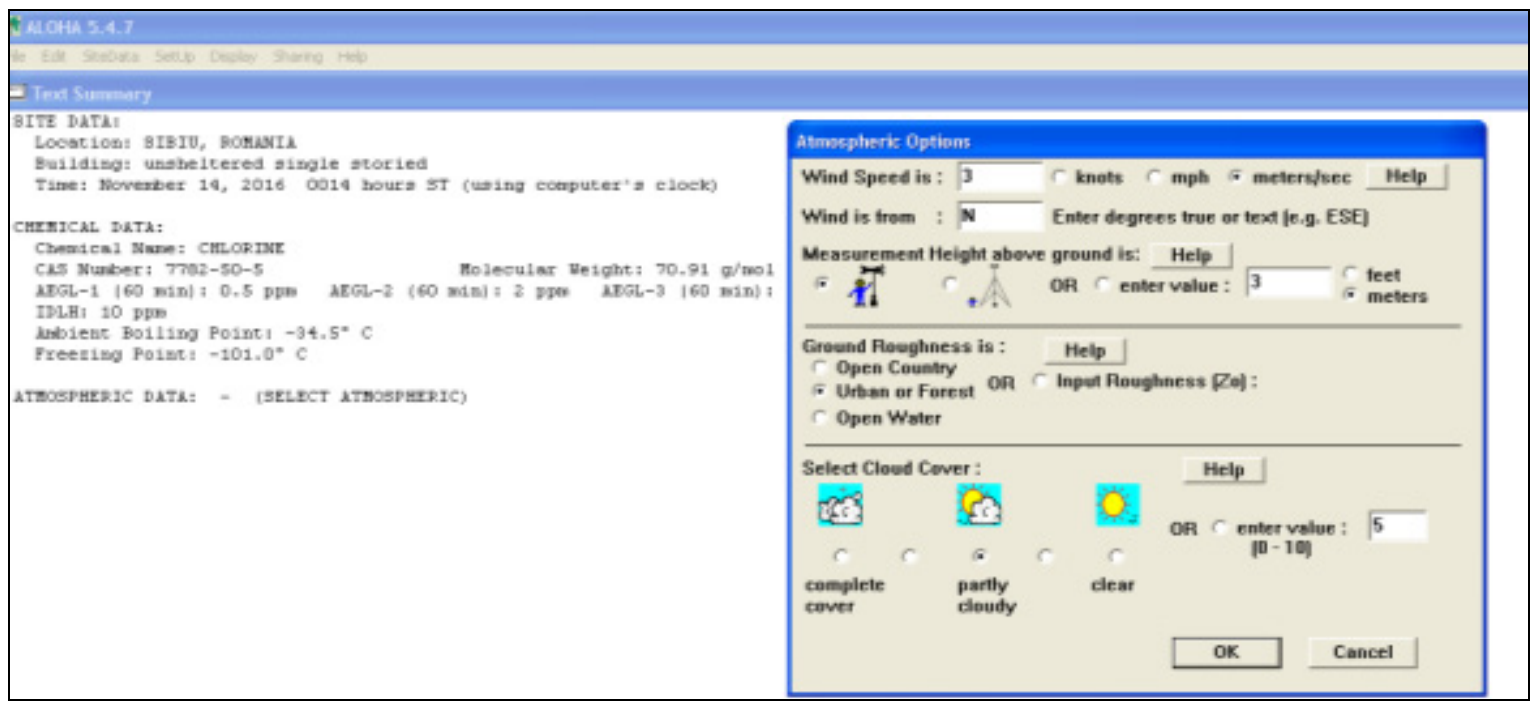

Figure no. 2. The atmospheric conditions set up

For next stage, (Figure no. 3) the application software will request data concerning the nature and type of danger source by choosing between: direct source, spill, tank and gas pipeline; the temperature at which the hazardous chemical was stored, as well as data about the tank volume, the fullness of the tank, its location, shape, size and the place of fracture.

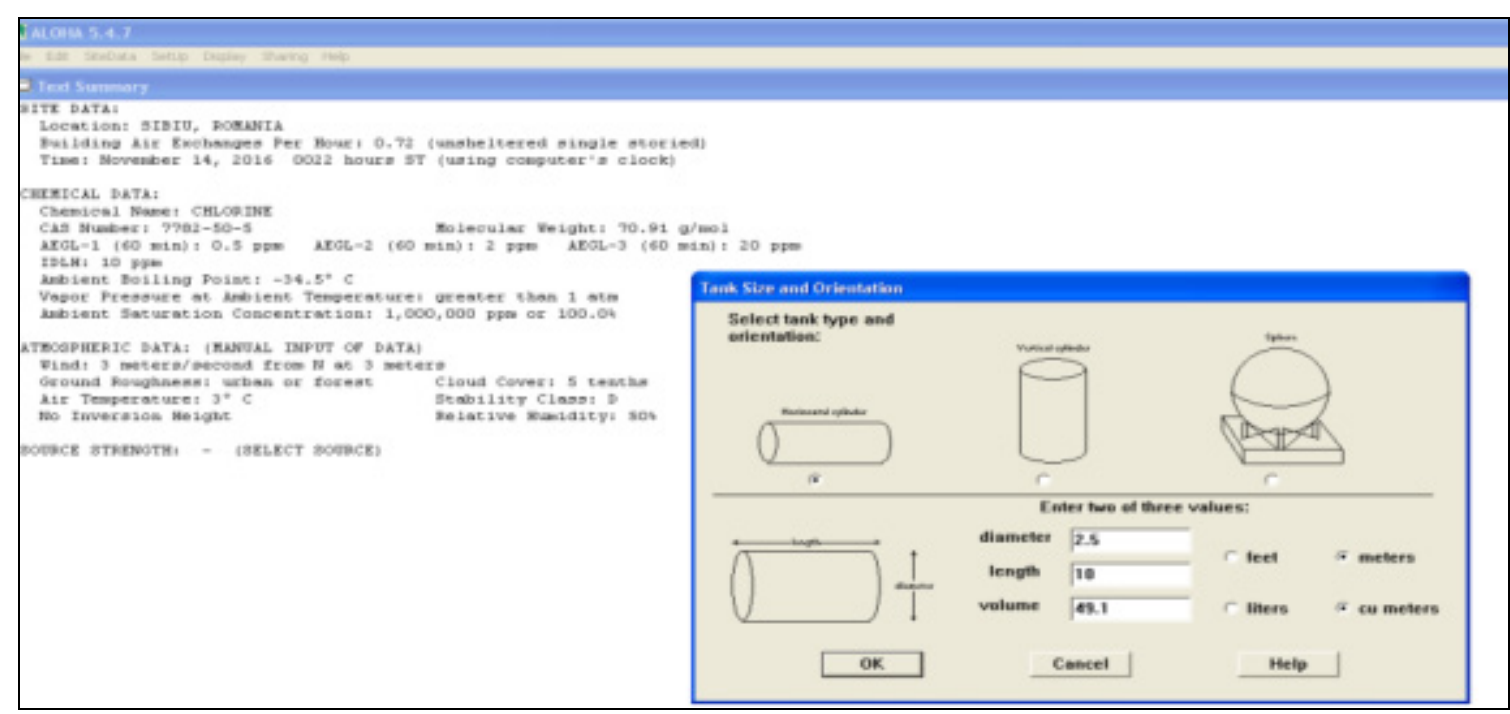

Figure no. 3. Modeling of container shape which contains the chemical

Following the analysis of the entered data, the application shows the rate of release into the environment of the chemical contaminant agent (Figure no. 4).
On a circular hole with a diameter of $2 \mathrm{~cm}$, located at least 0.83 meters above the reservoir, the maximum release rate of toxic into the environment is about $349 \mathrm{~kg} / \mathrm{min}$, 
and the maximum amount that can be

of hazardous chemical. released within one hour is about $20,594 \mathrm{~kg}$

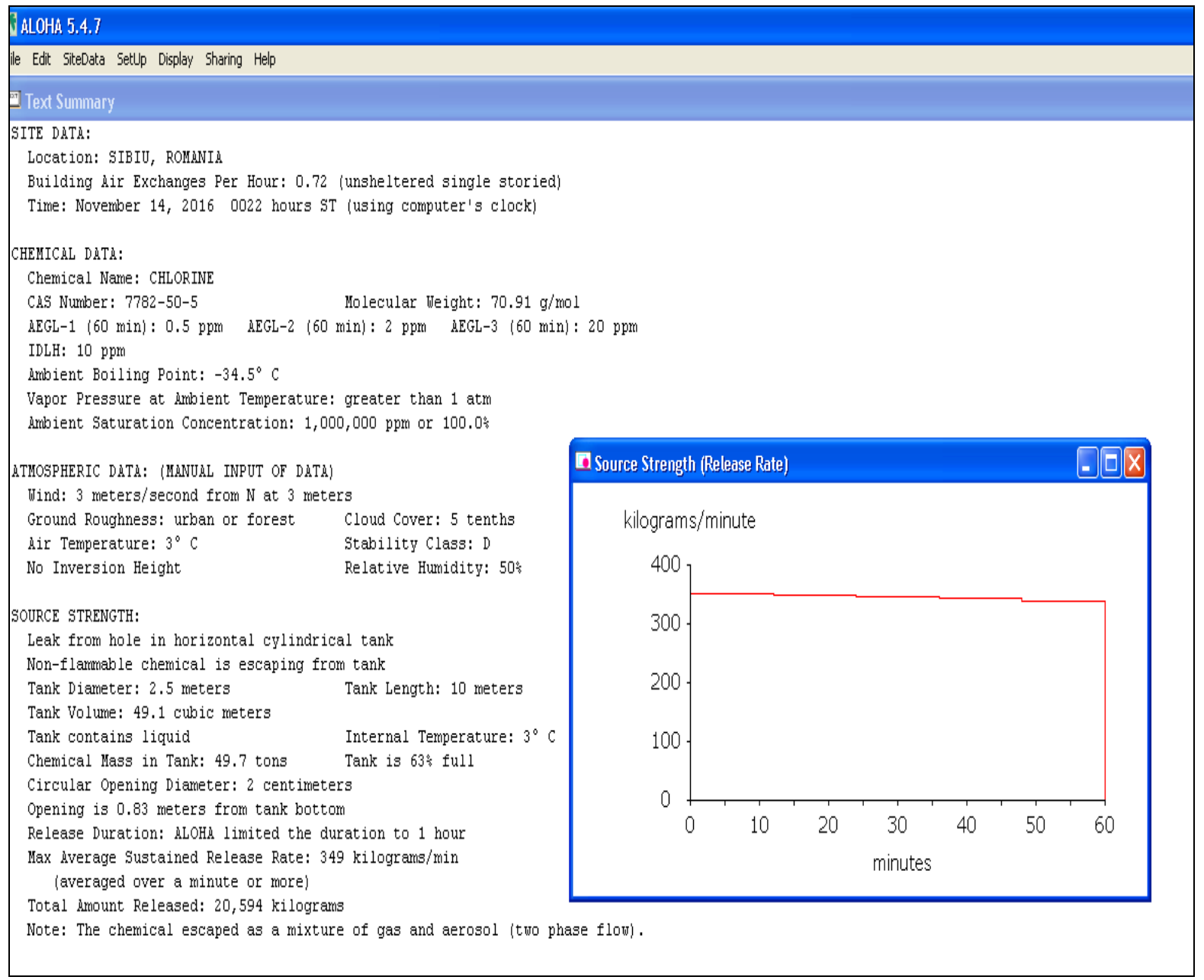

Figure no. 4. The releasing rate of chemical agent into the environment

Other significant information presented by this application software is related to releasing into the atmosphere of a mixture of gas and aerosol called the flow, in two stages, which is a very important detail for organizing the intervention on event site.
The software generates graphic simulation of risk areas (Figure no. 5) based on the Toxic Level of Concern (TLC), the user having the opportunity to select from the levels of Emergency Response Planning Guidelines (ERPGs) and the Acute Exposure Guideline Levels (AEGLs). 


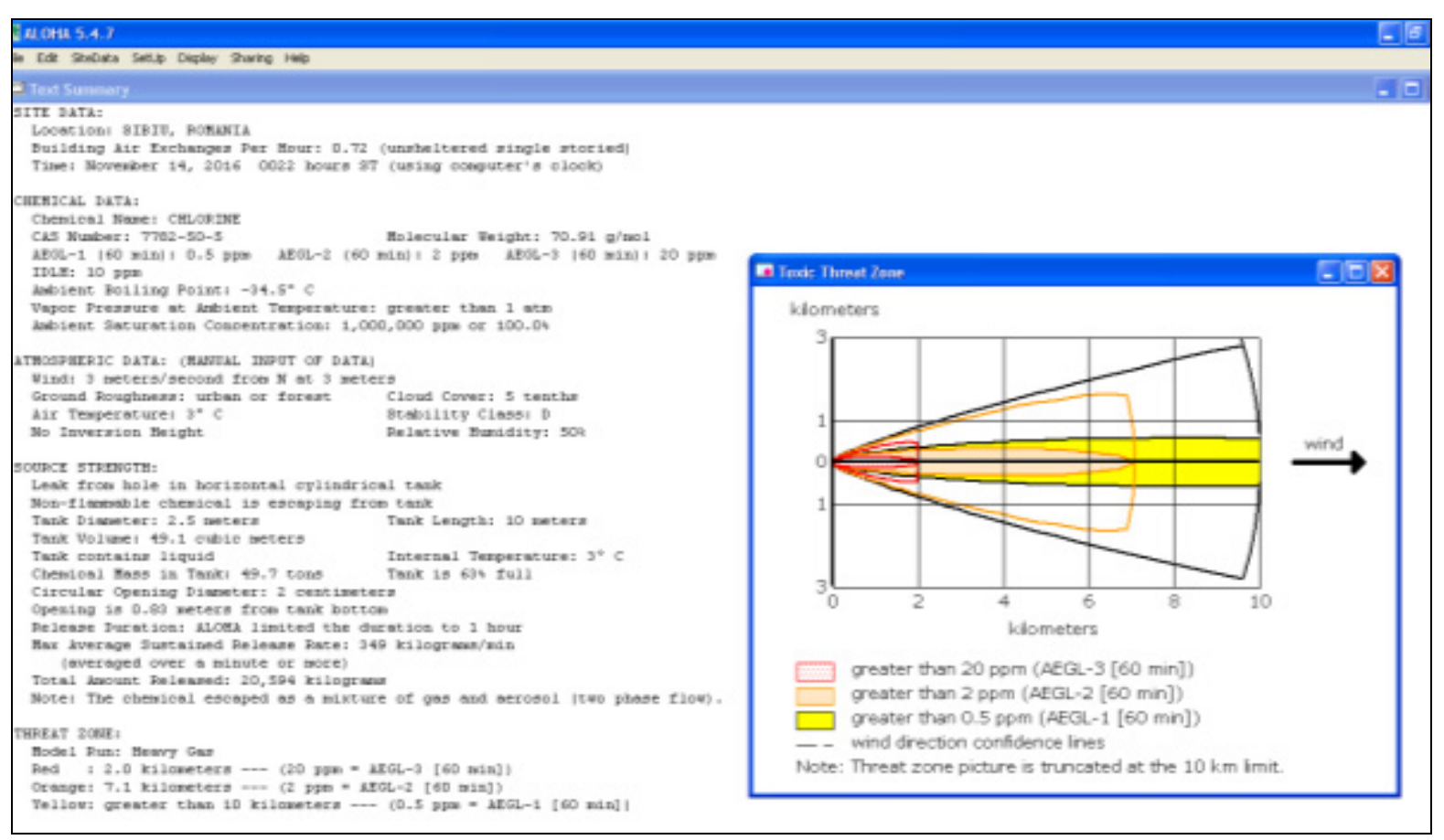

Figure no. 5. Graphic simulation of risk areas

To perform a simulation as realistic as possible, the software enables design risk areas arising from the analysis on a real map, thus providing essential information on areas affected by the occurrence of the event and the risks encountered by those living persons in the area or passing persons through such contaminated zone (Figure no. 6).

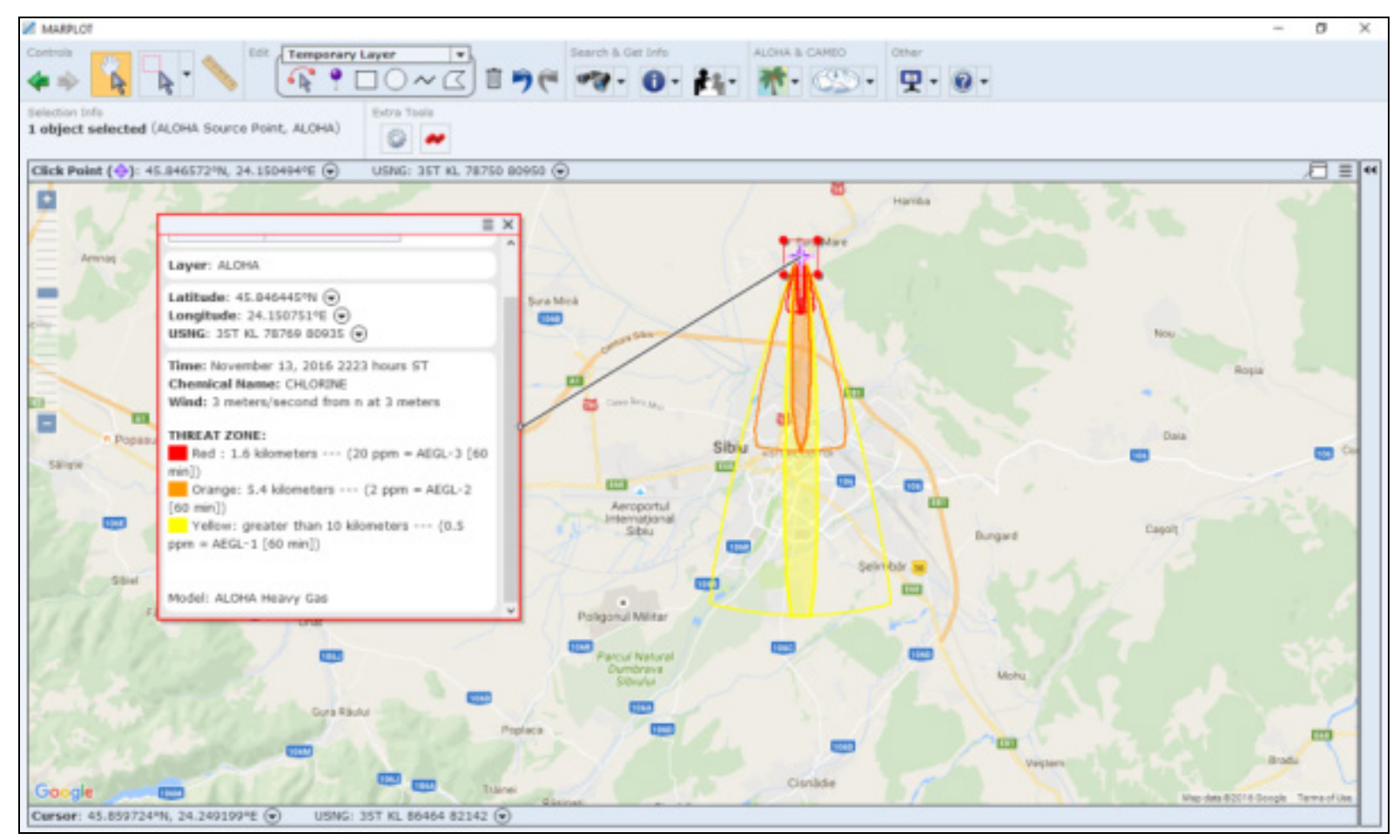

Figure no. 6. Integrated risks' analysis associated to scenario 


\section{Conclusion}

This paper was conceived, developed, and elaborated in an integrated harmonious manner by the team of authors as a scientific landmark useful to the specialists, based on the expertise in the field of the authors, taking in consideration the knowledge dialogue of investigated domain, by the issues addressed and resolved, especially through its implications on the improvement possibilities of organizational performances within institutions holding critical infrastructure. This is the domain were the outcomes of research could be placed in a relevant and pragmatic way. Through this paper is also indicated a strong need for using the powerful software to perform complex analyzes, starting from possible situations, which could form the basis for drawing up of the critical infrastructure operator security plan.

\section{REFERENCES}

Bunilă, I. (2013). Explozia de la Mihăileşti plasează Buzăul în istoria catastrofelor din România, available at: http://adevarul.ro/locale/buzau/video-foto-explozia-mihailesti-plaseazabuzaul-istoria-catastrofelor-romania-1 51be28e2c7b855ff569aca3e/index.html.

Erdal, C. \& Marincic, D. (2009). Computer Assisted Exercises and Training. A Reference Guide, New Jersey: John Wiley \& Sons, Inc.

European Commission. (2013). Horizon 2020, available at: http://ec.europa.eu/ programmes/horizon2020/h2020-sections.

Gurza, V.G. (2015). Urban Security, available at https://prezi.com/re4snl5t0lky/ securitatea-urbana.

Homeland Security. (2010). Chemical Sector-Specific Plan. An Annex to the National Infrastructure Protection Plan, available at: https://www.hsdl.org/?view\&did=7992.

Jurnal Vâlcean. (2016). Exerciţiu-accident cu substanţe periculoase pe Platforma Chimică, available at: http://jurnalvalcean.ro/exercitiu-accident-cu-substante-periculoase-peplatforma-chimica/.

Presidencial Administration. (2015). Strategia Naţională de apărare a ţării pentru perioada 2015-2019, available at: http://www.presidency.ro/files/userfiles/Strategia Nationala de Aparare a Tarii 1.pdf.

The U.S. Department of Transportation's. (2016). Emergency Response Guidebook. available at: https://www.transportation.gov/briefing-room/dot-releases-new-emergencyresponse-guidebook.

US Environmental Protection Agency. (2016). ALOHA Software, available at: https://www.epa.gov/cameo/aloha-software.

Virca, I. (2014). Curs de legislaţie rutieră pentru cat. B și C, Sibiu: Academia Forţelor Terestre "Nicolae Bălcescu".

Virca, I. \& Mihăilă, I.B. (2013). Analysis armored threats in the theaters of operations and ways to reduce their vulnerability, Revista Academiei Forţelor Terestre, Vol. XVIII, no. 2 (70), 215-220. 